Green conversion of saponins to diosgenin in an alcoholysis system catalyzed by solid acid derived from phosphorus tailings

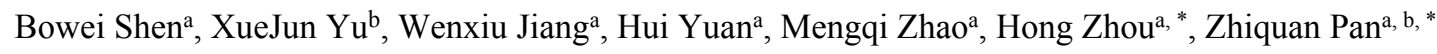

${ }^{a}$ College of Chemistry and Environmental Technology, Wuhan Institute of Technology, Wuhan

430073, China

${ }^{\mathrm{b}}$ Three Gorges Public Inspection and Testing Center, Hubei, China

\title{
FT-IR analysis
}

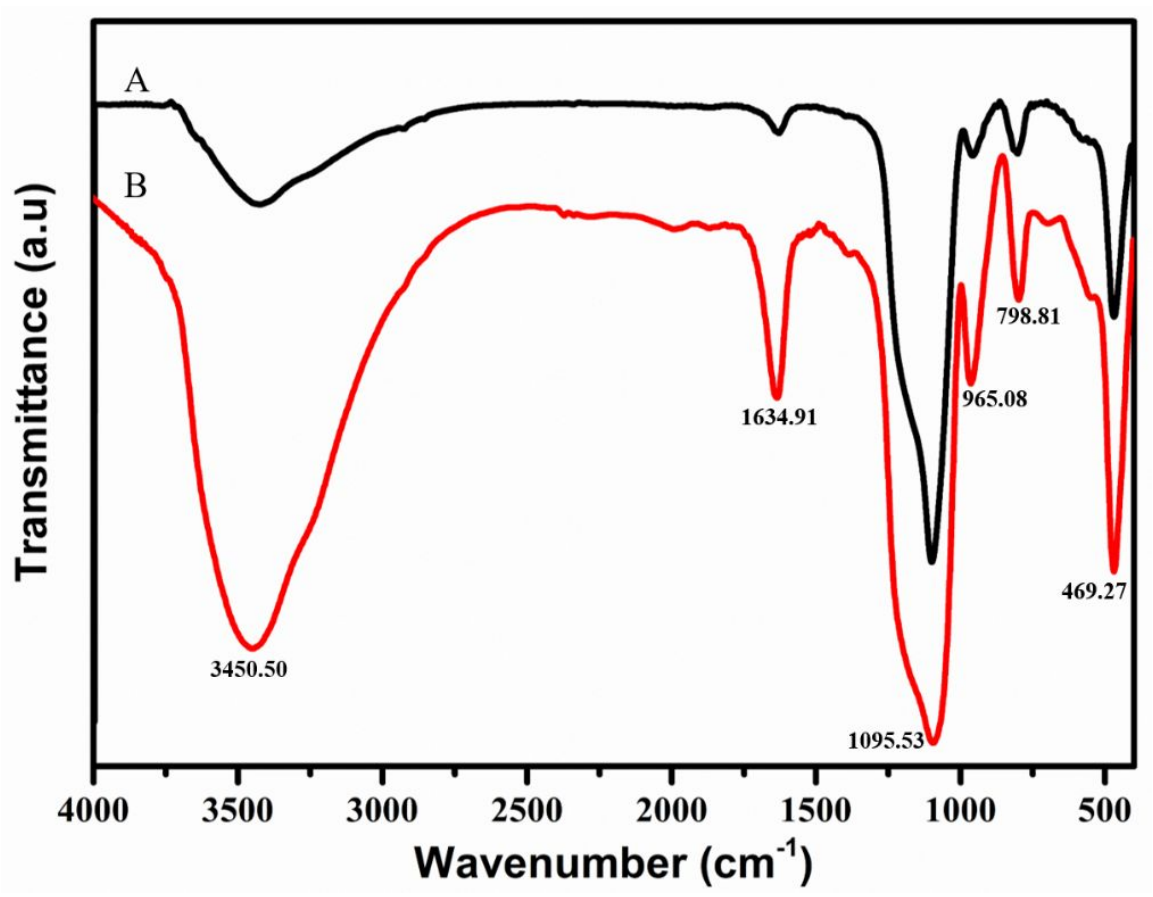

Figure.S1. FT-IR analysis (a) $\mathrm{SiO}_{2} ;$ (b) $\mathrm{SiO}_{2}-\mathrm{SO}_{3} \mathrm{H}$ 
TGA analysis

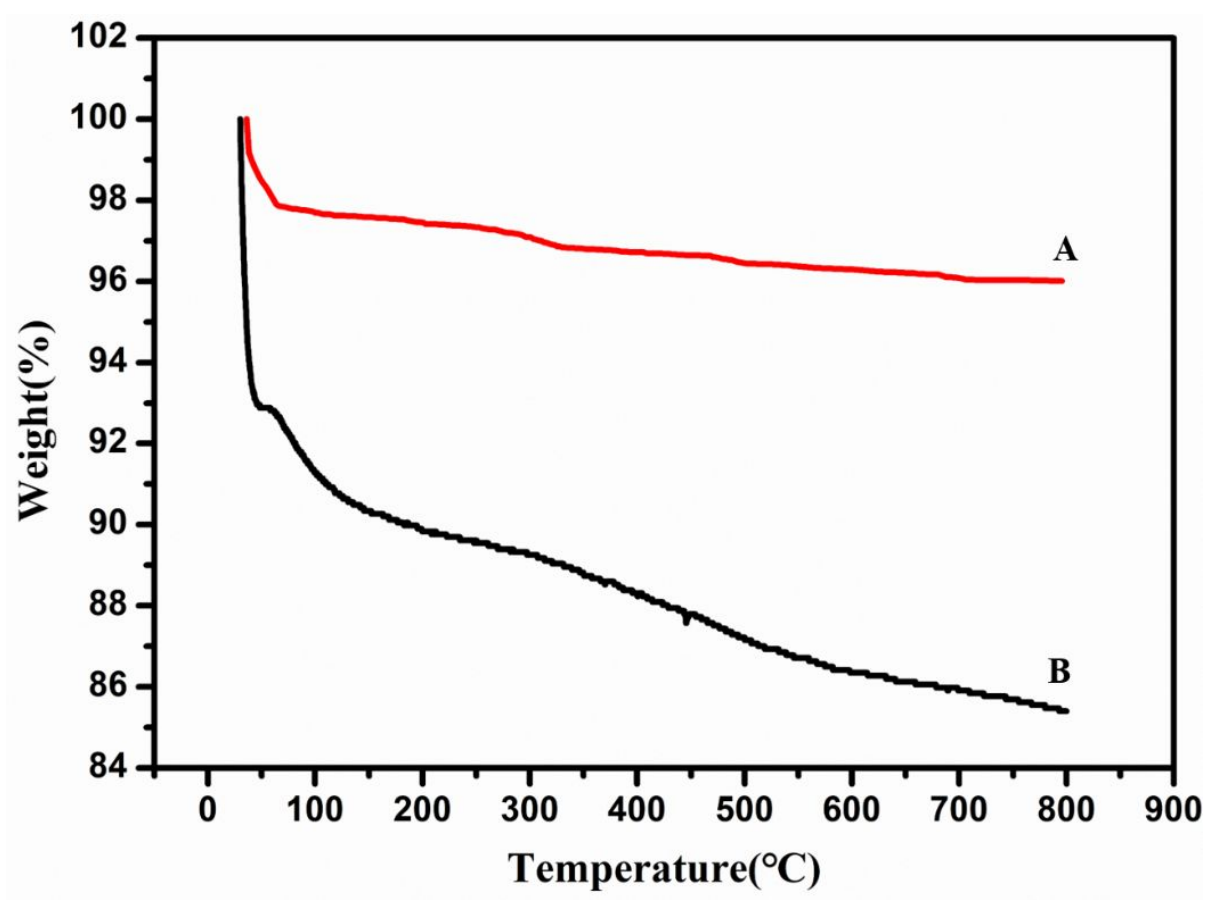

Figure.S2 TGA of (A) $\mathrm{SiO}_{2}$; (B) $\mathrm{SiO}_{2}-\mathrm{SO}_{3} \mathrm{H}$

\section{XRD analysis}

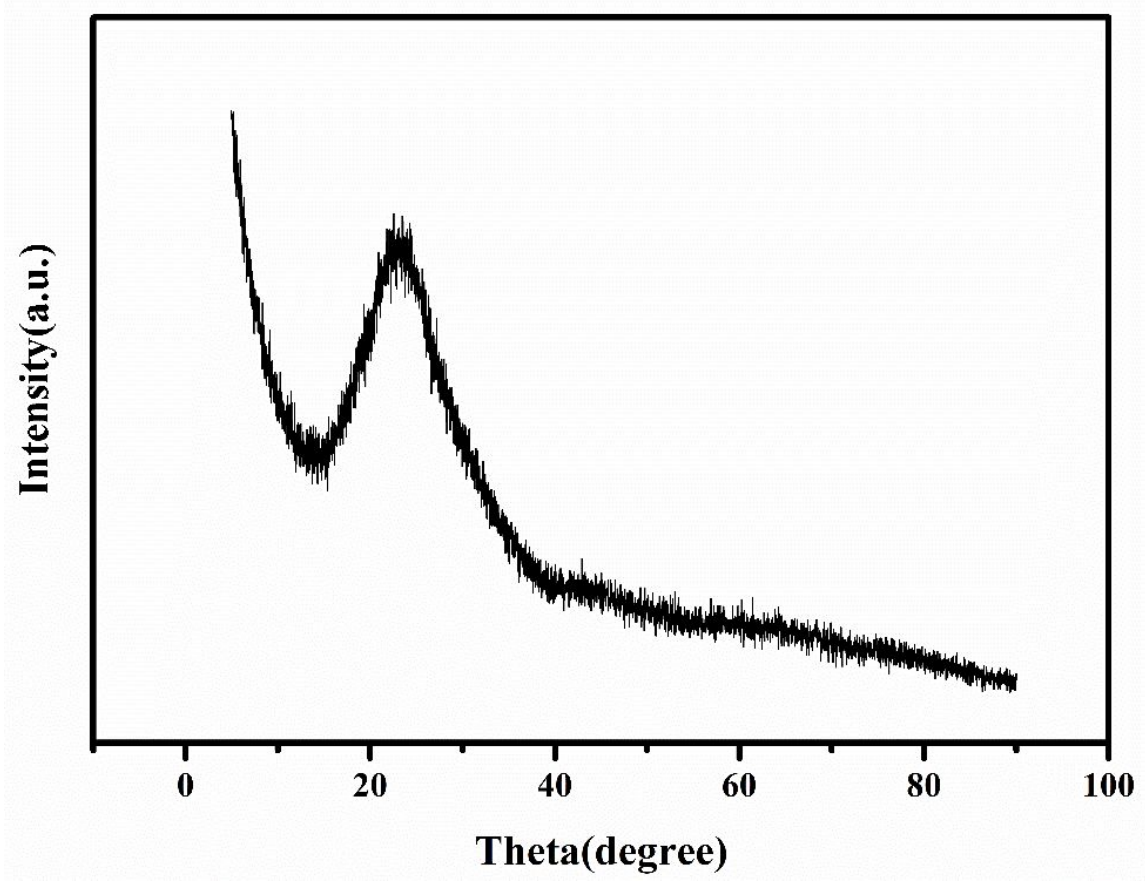

Figure.S3 XRD of $\mathrm{SiO}_{2}-\mathrm{SO}_{3} \mathrm{H}$ 


\section{LC-MS analysis}
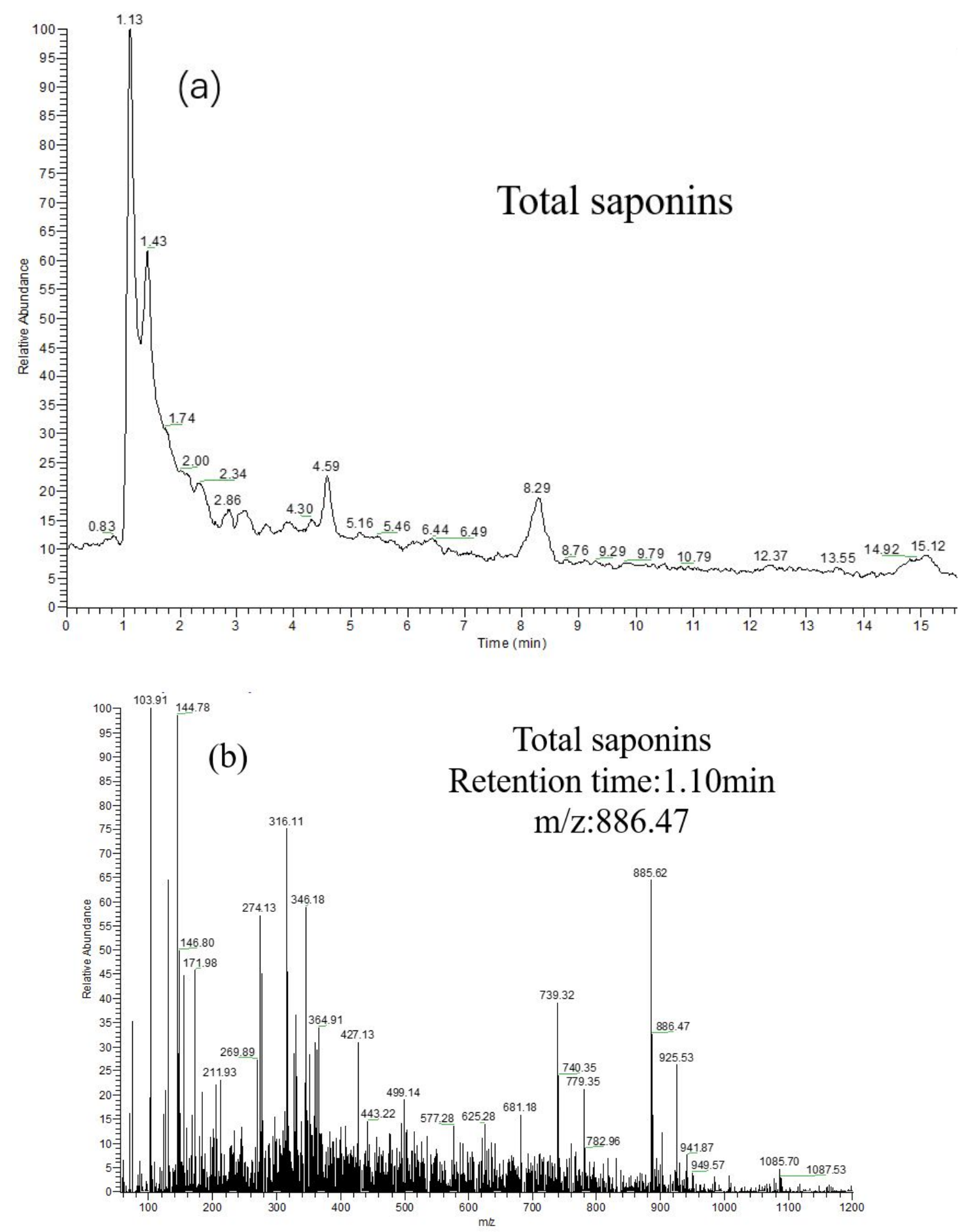

Figure.S4 (a) Total ion chromatogram (TIC) of total saponins; (b) the mass spectrogram of total saponins $(\mathrm{t}=1.10 \mathrm{~min})$. 

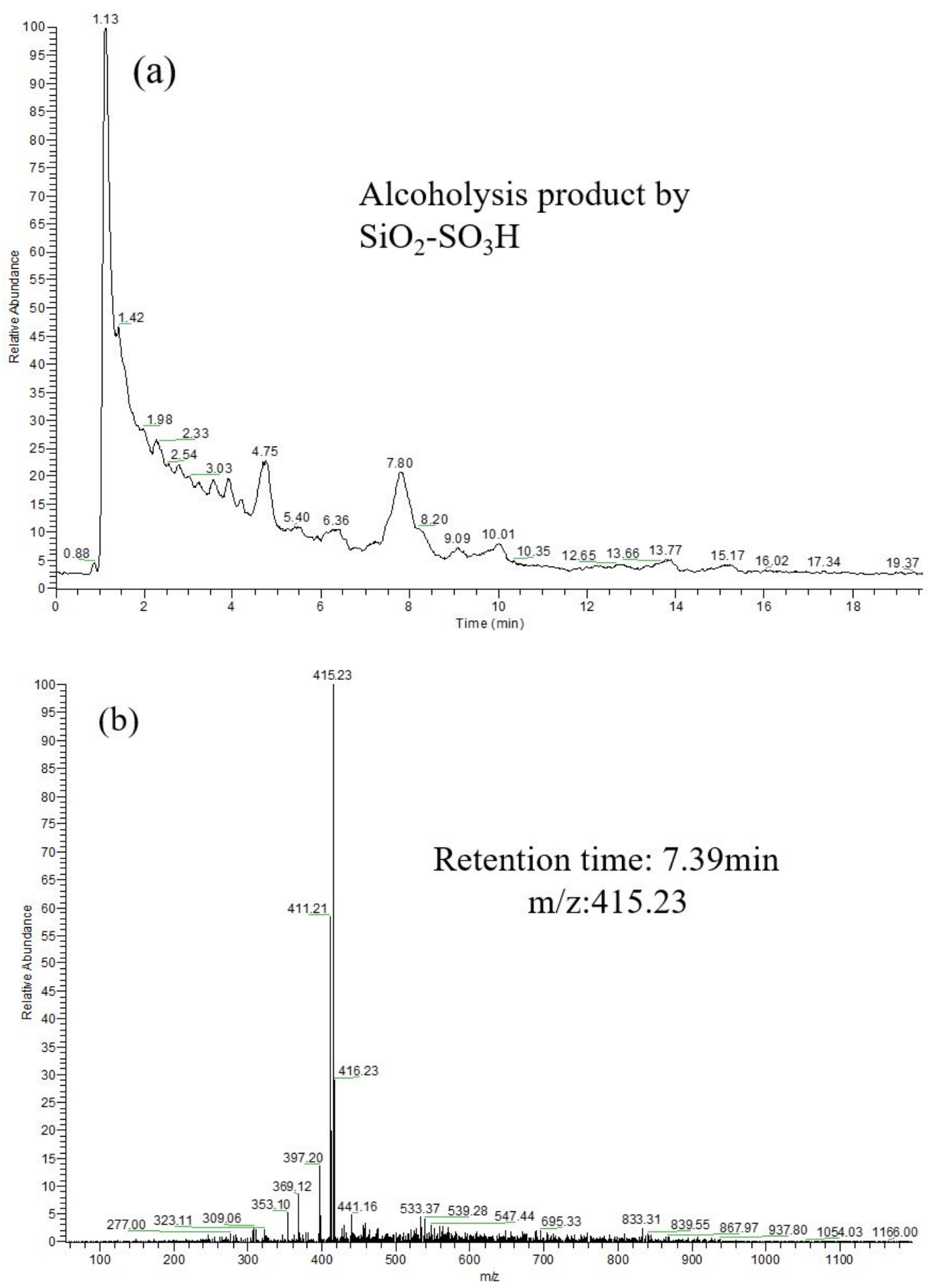

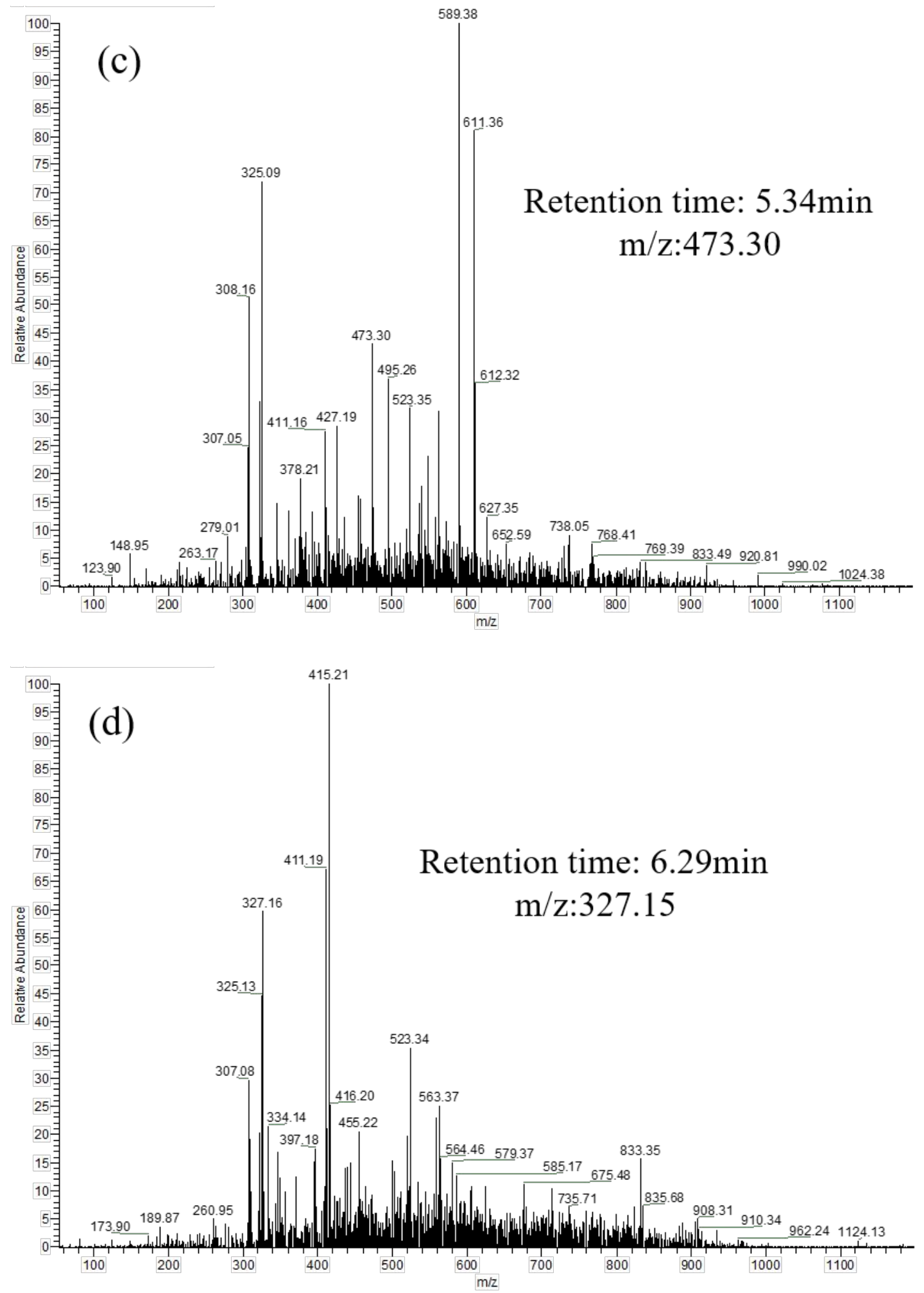

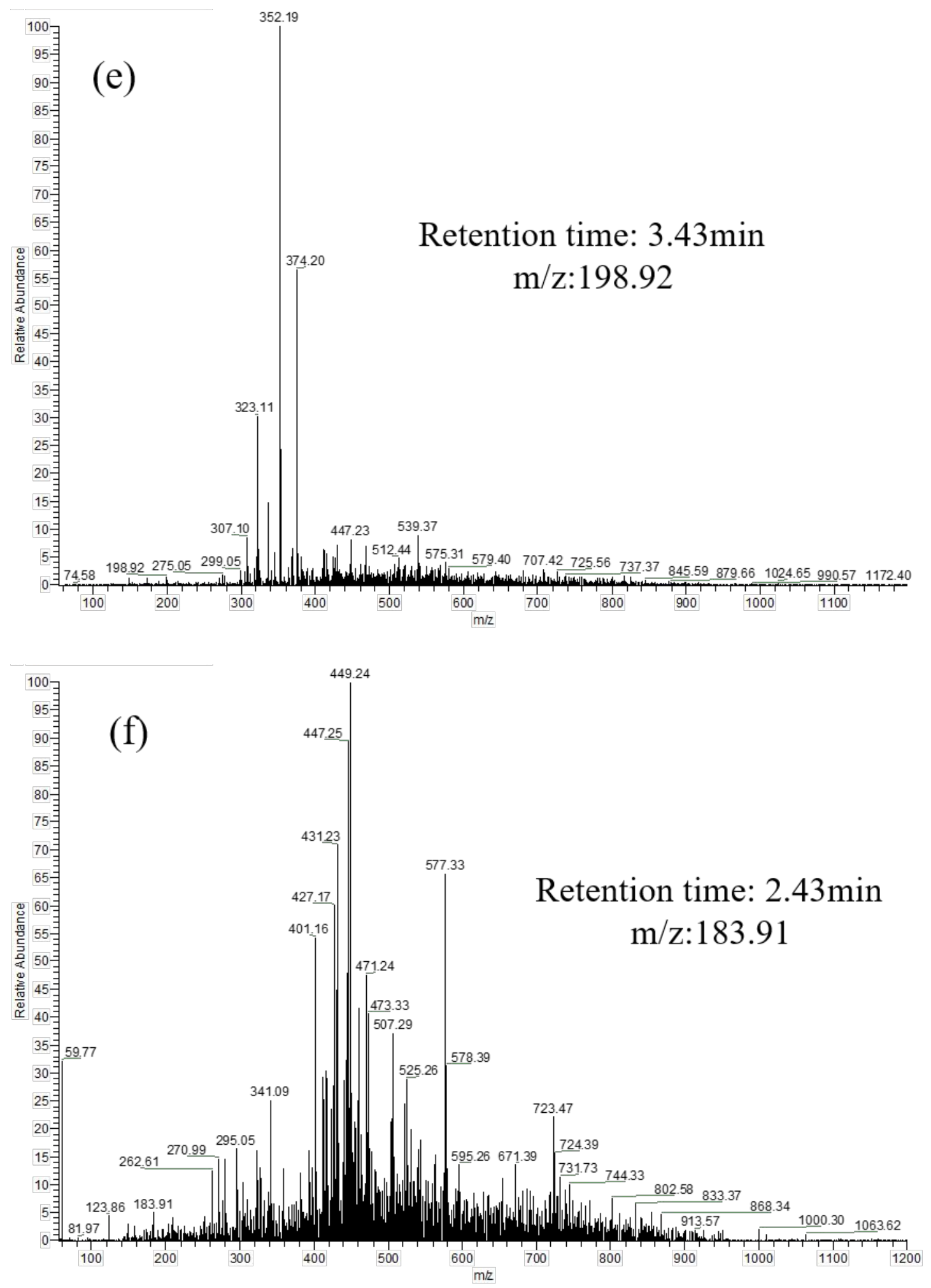

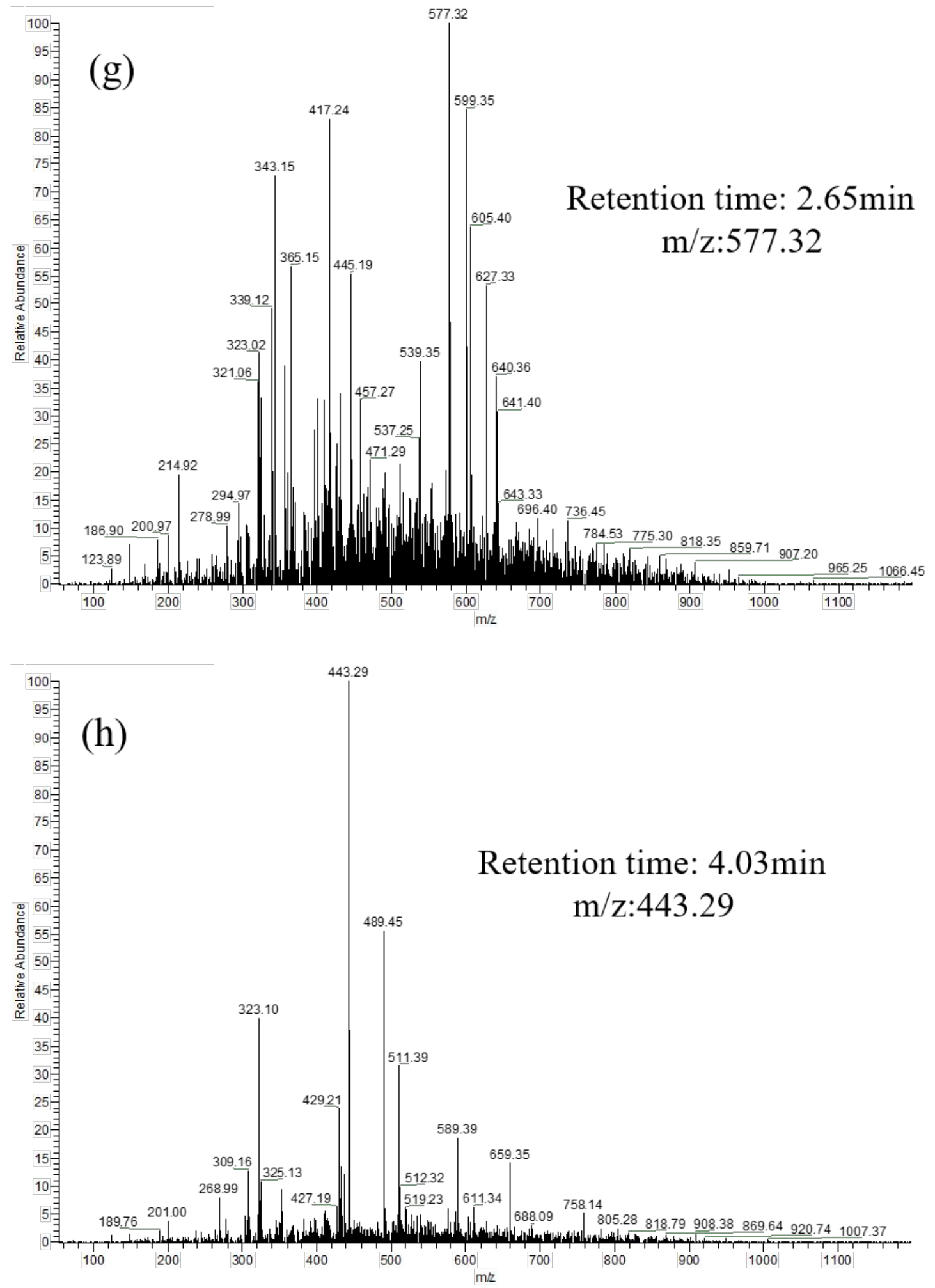

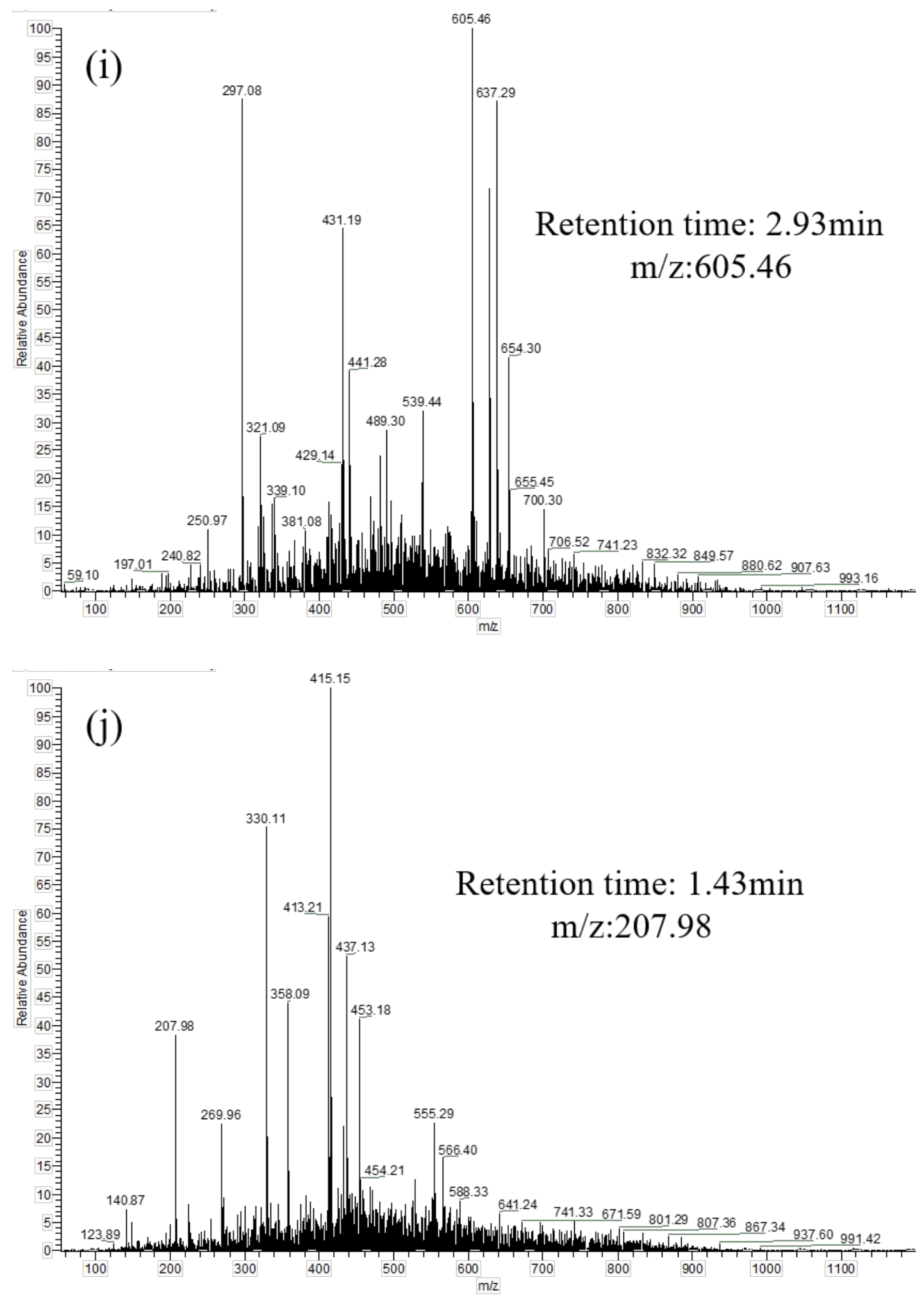

Figure.S5 (a) Total ion chromatogram (TIC) of alcoholysis products; (b-j) the mass spectrogram of alcoholysis products of pathway 